Tropical Journal of Pharmaceutical Research June 2016; 15 (6): 1115-1121

ISSN: $1596-5996$ (print); 1596-9827 (electronic) (C) Pharmacotherapy Group, Faculty of Pharmacy, University of Benin, Benin City, 300001 Nigeria. All rights reserved.

\title{
Formulation and stability of topical water in oil emulsion containing corn silk extract
}

\author{
Sabeeh Mohsin ${ }^{1,2 *}$, Naveed Akhtar ${ }^{1}$, Tariq Mahmood ${ }^{3}$, Hira Khan ${ }^{1}$, Rehan \\ Mustafa $^{1}$ \\ ${ }^{1}$ Department of Pharmacy, Faculty of Pharmacy and Alternative Medicine, The Islamia University of Bahawalpur, Bahawalpur \\ 63100, ${ }^{2}$ Department of Pharmaceutical Sciences, COMSATS Institute of Information Technology, Abbottabad 22010, ${ }^{3}$ Faculty \\ of Pharmacy, University of Central Punjab, Lahore, 54000, Pakistan
}

*For correspondence: Email: sabeehmohsin@gmail.com; Tel: +92 3007810290

\begin{abstract}
Purpose: To formulate the water in oil (W/O) emulsion of corn silk (CS) extract and to evaluate its stability at various storage conditions.

Methods: Ethanol CS extract was prepared using maceration (cold) technique. A $4 \%$ CS emulsion was prepared using varying concentrations of liquid paraffin, ABIL EM90 and water. The formulations were kept at $25{ }^{\circ} \mathrm{C}$ for 28 days and to screen out the less stable formulations. The remaining formulations were further stressed at $40^{\circ} \mathrm{C}$ to choose the most stable formulation. The optimized formulation was evaluated for physical characteristics including phase separation, rheology and mean droplet size. The physical stability of the formulation was evaluated by monitoring these parameters over a period of 12 weeks at $8,25,40$ and $40^{\circ} \mathrm{C}$, and $75 \% \mathrm{RH}$.

Results: The chosen formulation showed good resistance to phase separation on centrifugation under all storage conditions. Rheological behavior followed non-Newtonian pseudoplastic pattern at various storage conditions. Mean droplet size of freshly prepared formulation was $2.98 \pm 1.32 \mu \mathrm{m}$ and did not show significant $(p<0.05)$ changes at normal storage conditions $\left(8\right.$ and $\left.25^{\circ} \mathrm{C}\right)$.

Conclusion: The findings indicate that the developed CS extract W/O emulsion is stable and therefore may be suitable for topical use on skin as an antioxidant preparation.
\end{abstract}

Keywords: Corn silk, Emulsion, Nonionic surfactant, Rheology, Flow index, Droplet size, NonNewtonian pseudoplastic

Tropical Journal of Pharmaceutical Research is indexed by Science Citation Index (SciSearch), Scopus, International Pharmaceutical Abstract, Chemical Abstracts, Embase, Index Copernicus, EBSCO, African Index Medicus, JournalSeek, Journal Citation Reports/Science Edition, Directory of Open Access Journals (DOAJ), African Journal Online, Bioline International, Open-J-Gate and Pharmacy Abstracts

\section{INTRODUCTION}

Emulsions are widely used in the pharmaceutical, cosmetic, food, petroleum and agriculture industry. Emulsion is a two phase system of immiscible liquids where one phase is distributed throughout the other in the form of small globules and the dispersion being stabilized by emulsifying agent. These emulsions may be designed as macroemulsion, multiple emulsion and microemulsions [1]. Semisolid emulsions or creams are frequently used for the topical delivery of active agents for producing desired effects locally in the skin [2]. These emulsions may be water in oil (W/O) or oil in water $(\mathrm{O} / \mathrm{W})$ which depends on the surfactant employed in the formulation [3].

Surfactants are chemical entities that impart stability by forming a thin, non-adhering film at boundary between two immiscible phases by lowering the interfacial tension [4]. The stability of 
emulsion is affected by number of factors including temperature, $\mathrm{pH}$ and bacterial growth during the manufacturing, storage and usage of the emulsion [5,6]. This instability is demonstrated as coalescence, flocculation, creaming, breaking and phase inversion [1]. It is challenge for the scientists to design formulations that are sufficiently stable against these phenomena during the period of use. In this quest various methods have been established to predict the stability and also to evaluate the influence of various factors involved during storage. Very common methods to investigate physical stability involve organoleptic, rheological and microscopic evaluations [4].

Chronic exposure of human skin to UV irradiation and other environmental hazards result in significant oxidative stress leading to harmful cosmetic and health effects $[7,8]$. The antioxidants from natural sources provide new opportunities to combat the adverse effects mediated by oxidative stress $[9,10]$. The use of herbal extracts in cosmetics and topical cures is as a result of associated lower side effects as compared to their synthetic counterparts that has increased customer acceptance for such products [11]

Corn silk refers to the brownish, thread like stigma of female flower of maize (Zea mays L., family Poaceae). Corn silk has been used as a kind of remedy for many ailments including chronic nephritis, diuretic agent, benign prostatic hyperplasia, gout, cystitis [12], heart problems, jaundice and malaria [13]. Studies have suggested the use of CS extract as natural antioxidant in the diseases caused by oxidative stress because of the presence of phytochemicals like phenolics and flavonoids [14].

The purpose of this study was to examine the influence of storage conditions like temperature on physical characteristics of W/O emulsion containing CS extract. Furthermore, formulation was stored for a period of 12 weeks and physical stability was evaluated by observing phase separation, rheology and droplet size of formulations under observation.

\section{EXPERIMENTAL}

\section{Plant material}

The corn silk was collected in the month of November 2014 from the District Bahawalpur, Pakistan. The plant material was botanically authenticated by taxonomist, Mr. Muhammad Sarwar, Department of Life Sciences, The Islamia University of Bahawalpur, Bahawalpur, Pakistan and the specimen (voucher no. 2393) was preserved in the herbarium of Department of Pharmacy, The Islamia University of Bahawalpur, Pakistan for future reference.

\section{Chemicals}

The lipophilic emulsifier, ABIL EM-90 (cetyl dimethicone Copolyol) was obtained from Evonik industries AG (Essen, Germany), liquid paraffin oil was purchased from Merck (Darmstadt, Germany), ethyl alcohol was supplied by BDH (Poole, England), 1,1-diphenyl-2-picrylhydrazyl (DPPH) was procured from Sigma-Aldrich (St. Louis, USA). Water was freshly distilled in Lab.

\section{Preparation of CS extract}

The plant material was air dried at ambient temperature for four weeks. Dried material was pulverized to homogeneous size. Dried corn silk powder $(80 \mathrm{~g})$ was macerated with $800 \mathrm{~mL}$ of ethanol for 1 week, at room temperature. Stirring was performed for 30 min once at the start of soaking and then at the completion of the process.

The material was separated from residues by layers of muslin cloth and later by passing through Whatman filter paper no. 45. The filtrate was evaporated under vacuum in a rotary evaporator at $45{ }^{\circ} \mathrm{C}$, until the volume was reduced to one third of the initial volume. Concentrate was refrigerated for development of formulation and further studies.

\section{DPPH photometric assay}

DPPH was used to determine the $\mathrm{H}$-donor potential of the corn silk extract following a method previously described with some modifications [15]. The method is based on the principle that DPPH color changes from purple to yellow after reduction by antioxidants. Ninety microliters of DPPH solution $(100 \mu \mathrm{M}$ in methanol) was added to $10 \mu \mathrm{L}$ of test ethanolic extract to a final volume of $100 \mu \mathrm{L}$, in a 96-well microtiter plate. Ninety microliters of DPPH solution added to $10 \mu \mathrm{L}$ of ethanol served as negative control. The reaction mixtures were stirred and kept for incubation at $37{ }^{\circ} \mathrm{C}$ in the dark. After $30 \mathrm{~min}$ the decrease in absorbance was measured photometrically at $517 \mathrm{~nm}$ with a microplate reader (Synergy-HT, BioTek, USA). Data obtained was computed on Ez-fit software. Scavenging activity was calculated as in Eq 1. 
Scavenging activity $(\%)=\left\{\left(A_{0}-A_{1}\right) / A_{0}\right\} 100 \ldots$ (1)

where $\mathrm{A}_{0}=$ absorbance of control and $\mathrm{A}_{1}=$ absorbance of test extract. L-ascorbic acid was used as reference standard.

\section{Preparation of CS emulsion}

Various formulation containing CS extract $4 \%$, ABIL EM90 2.5 - $5 \%$, liquid paraffin $8-16 \%$ and water $76-84 \%$ were prepared by heating the aqueous phase (water and CS extract) and the oily phase (liquid paraffin and ABIL EM90) separately at temperature of $70{ }^{\circ} \mathrm{C}$ to $75{ }^{\circ} \mathrm{C}$. The oily phase was then added to the aqueous phase gradually. Mixing was carried out at $2000 \mathrm{rpm}$ for 25 min using overhead stirrer (Stirrer type BS, Velp scientifica, Italy) until emulsion solidified.

The formulation was further stirred at $1000 \mathrm{rpm}$ for $5 \mathrm{~min}$ and then $500 \mathrm{rpm}$ for $10 \mathrm{~min}$ to accomplish the homogenization. The optimized formulation was selected by first storing the formulation at $25{ }^{\circ} \mathrm{C}$ for a period of 28 days. The stable formulations after the initial stress test were further stored at $40{ }^{\circ} \mathrm{C}$ to obtain the most stable W/O emulsion (CS extract $4 \%$, ABIL EM90 $2.5 \%$, liquid paraffin $10 \%$, and distilled water $83.5 \%$ ).

\section{Characterization and stability of CS emulsion}

\section{Centrifugation test}

Centrifugation test was carried out by placing $2 \mathrm{~g}$ of formulation and base, stored at different conditions, in the $15 \mathrm{ml}$ centrifuge tube and centrifuged for two runs of $10 \mathrm{~min}$, at $5000 \mathrm{rpm}$ in centrifugation machine (EBA 20, Hettich, Germany). At the end of each cycle, tubes were investigated macroscopically for the presence of any possible phase separation.

\section{Rheological measurements}

Rheological properties of the formulation were investigated using a cone and plate type rheometer (DV- III Ultra, Brookfield engineering laboratory, USA) equipped with a circulating system for temperature control. Rheological measurements were made at $25 \pm 1{ }^{\circ} \mathrm{C}$ using a CP41 spindle. Shear rate was progressively increased from $20-86 \mathrm{~s}^{-1}$ to construct the rheograms and data obtained was mathematically analyzed by a Brookfield programme, Rheocalc version V 1.01 (Brookfield engineering, USA) according to the Power law analysis as in and IPC Paste analysis as in Eqs 2 and 3 , respectively.
$\mathrm{T}=\mathrm{k} \mathrm{D}^{\mathrm{n}}$

Where is $T$ shear stress, $D$ is shear rate, $k$ is consistency index and $\mathrm{n}$ is the flow index.

$H=\beta R^{S}$

where $\eta$ is shear viscosity, $R$ is the rotational speed, $s$ is the shear sensitivity factor and $\beta$ is consistency multiplier.

\section{Microscopy}

The emulsion morphology and particle size was determined through an optical microscope (Eclipse E200, Nikon, Japan) coupled to a high resolution digital camera. Micrographs were collected by using Minisee version 1.1 (Scop Tek Minisee, Japan) image analyzing software, at $100 \times$ magnification. A small quantity of W/O emulsion was smeared on the glass slide and diluted it with external phase. Samples were covered by cover slip with care to avoid sample damage by shear stress.

The mean droplet size was reported by using calibrated ocular micrometer. The data was obtained from more than 50 globules from various micrographs of the sample.

\section{Stability studies}

Stability studies were performed on the optimized CS extract emulsion to assess their physical stabilities. The W/O emulsion was stored at 8, 25,40 and $40{ }^{\circ} \mathrm{C} \pm 75 \%$ for a period of twelve weeks. The samples were withdrawn at regular intervals of 4,8 , and 12 weeks of investigation and evaluated for phase separation on centrifugation, changes in rheological parameters, and globule size.

\section{Data analysis}

All the results are presented as mean \pm standard deviation (SD). Image analyzing software (Digimizer) was used to perform particle size analysis. One-way analysis of variance (ANOVA) was used to analyze the data for rheology. The level of significance adopted was $p<0.05$.

\section{RESULTS}

\section{Antioxidant activity}

The results of DPPH photometric assay showed good antioxidant potential of the extract and formulation. The \% DPPH activity plateaued at $81.5 \pm 0.93$ and $75.06 \pm 1.27$ for CS extract and CS emulsion, respectively. 
Table 1: Sedimentation of CS emulsion at various time intervals

\begin{tabular}{lcccc}
\hline Storage & \multicolumn{4}{c}{ Temperature } \\
\cline { 2 - 5 } period & $\mathbf{8}^{\circ} \mathbf{C}$ & $\mathbf{2 5} \mathbf{C}$ & $\mathbf{4 0} \mathbf{C}$ & $\mathbf{4 0}{ }^{\circ} \mathbf{C} \pm \mathbf{7 5} \% \mathbf{R H}$ \\
\hline Freshly & -- & -- & -- & -- \\
prepared & & & & \\
formulation & -- & -- & -- & -- \\
4 weeks & -- & -- & -- & -+ \\
8 weeks & -- & -- & -+ & -+ \\
12 weeks & - &
\end{tabular}

* -- = No Phase separation; -+ =Phase separation after $20 \mathrm{~min}$; ++ phase separation after $10 \mathrm{~min}$

\section{Centrifugation test}

The formulation showed good long term stability as no phase separation was observed when freshly prepared emulsion was studied under experimental conditions. Table 1 presents the effect of storage conditions after various time intervals on the formulation. It is observed that formulation, kept at 8 and $25{ }^{\circ} \mathrm{C}$, did not show any phase separation at the completion of study. Higher temperatures $\left(40\right.$ and $\left.40{ }^{\circ} \mathrm{C} \pm 75 \% \mathrm{RH}\right)$, however has influenced the stability as phase separation was observed after the 12 th week and 8th week of study respectively.

\section{Rheological properties}

The relationship between shear stress and shear rate for formulation at various experimental conditions after different time intervals is shown in Figure 1. It is apparent that flow curves were non-linear which is indicative of non-Newtonian, pseudoplastic behavior of formulation during study. Such characteristic is desired in the topically used pharmaceutical and cosmetic products. The flow pattern was observed to be similar after study period but variation in consistency was observed.

The values of rheological parameters are presented in Table 2. The consistency index $(\mathrm{Cl})$, flow index $(\mathrm{FI}), 10 \mathrm{rpm}$ viscosity $(\mathrm{V})$ and shear sensitivity (SS) values were in the range of 1372 - 541.4, $0.45-0.40,265.1-182.9$ and 0.55 0.32 , respectively. The confidence of fit was in the range of 97.0 - 99.6 for the Power Law and IPC Paste analysis.
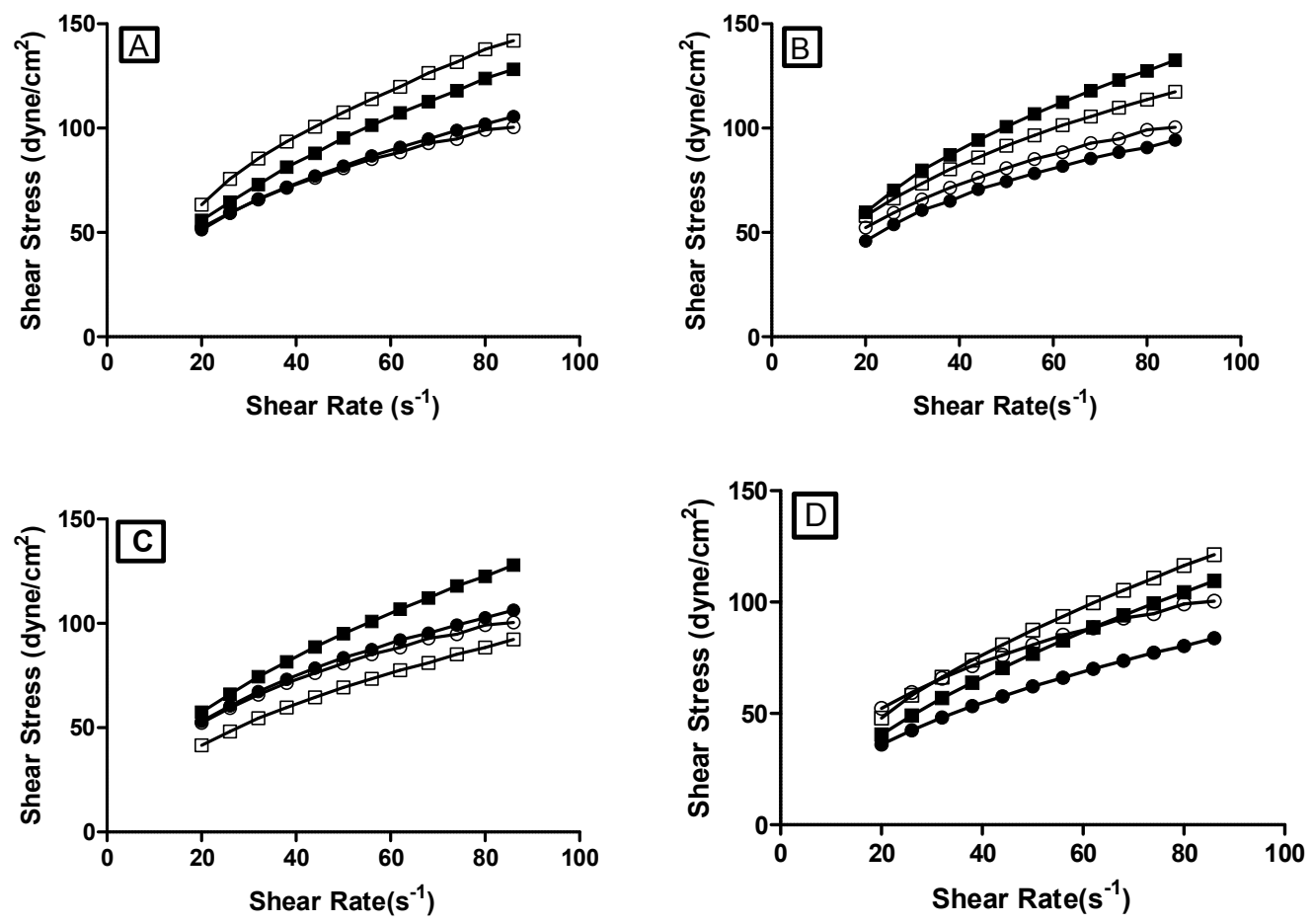

Figure 1: Rheogram of formulation at various time intervals stored at (A) $8{ }^{\circ} \mathrm{C}$, (B) $25{ }^{\circ} \mathrm{C}$ (C) $40{ }^{\circ} \mathrm{C},(\mathrm{D}) 40{ }^{\circ} \mathrm{C} \pm$

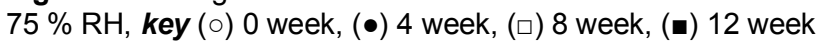


Table 2: Rheological parameters of CS Emulsion at various time intervals

\begin{tabular}{|c|c|c|c|c|c|c|c|}
\hline \multirow[t]{3}{*}{ Storage period } & \multirow{3}{*}{$\begin{array}{c}\text { Temperature } \\
\left({ }^{\circ} \mathrm{C}\right)\end{array}$} & \multicolumn{6}{|c|}{ Rheological parameter } \\
\hline & & \multicolumn{3}{|c|}{ Power law analysis } & \multicolumn{3}{|c|}{ IPC paste analysis } \\
\hline & & $\mathrm{Cl}$ & $F I$ & $C F$ & $\boldsymbol{V}$ & SS & $C F$ \\
\hline $\begin{array}{l}\text { Freshly prepared } \\
\text { formulation }\end{array}$ & & 1372 & 0.45 & 99.3 & 265.1 & 0.55 & 99.2 \\
\hline \multirow[t]{4}{*}{4 weeks } & 8 & 1197 & 0.49 & 99.5 & 260 & 0.51 & 299.5 \\
\hline & 25 & 1127 & 0.48 & 98.8 & 237.2 & 0.52 & 98.8 \\
\hline & 40 & 3335 & 0.40 & 99.2 & 332.2 & 0.56 & 99.6 \\
\hline & $40 \pm 75 \%$ RH & 650.1 & 0.57 & 99.5 & 182.9 & 0.43 & 99.5 \\
\hline \multirow[t]{4}{*}{8 weeks } & 8 & 1289 & 0.54 & 99.1 & 326 & 0.46 & 99.1 \\
\hline & 25 & 1376 & 0.48 & 99.6 & 292.4 & 0.52 & 99.6 \\
\hline & 40 & 822.2 & 0.54 & 99.6 & 209.5 & 0.46 & 99.6 \\
\hline & $40 \pm 75 \% \mathrm{RH}$ & 747 & 0.63 & 99.3 & 244.8 & 0.37 & 99.3 \\
\hline \multirow[t]{4}{*}{12 weeks } & 8 & 999.6 & 0.57 & 99.6 & 279 & 0.43 & 99.6 \\
\hline & 25 & 1217 & 0.54 & 99.2 & 305 & 0.46 & 99.2 \\
\hline & 40 & 843 & 0.57 & 97.0 & 235 & 0.43 & 97.0 \\
\hline & $40 \pm 75 \% \mathrm{RH}$ & 541.4 & 0.68 & 99.5 & 203.6 & 0.32 & 99.5 \\
\hline
\end{tabular}

${ }^{*} \mathrm{Cl}=$ Consistency index (cP); Fl=Flow Index; CF= Confidence of fit (\%); V=10 rpm viscosity (cP); SS=Shear sensitivity
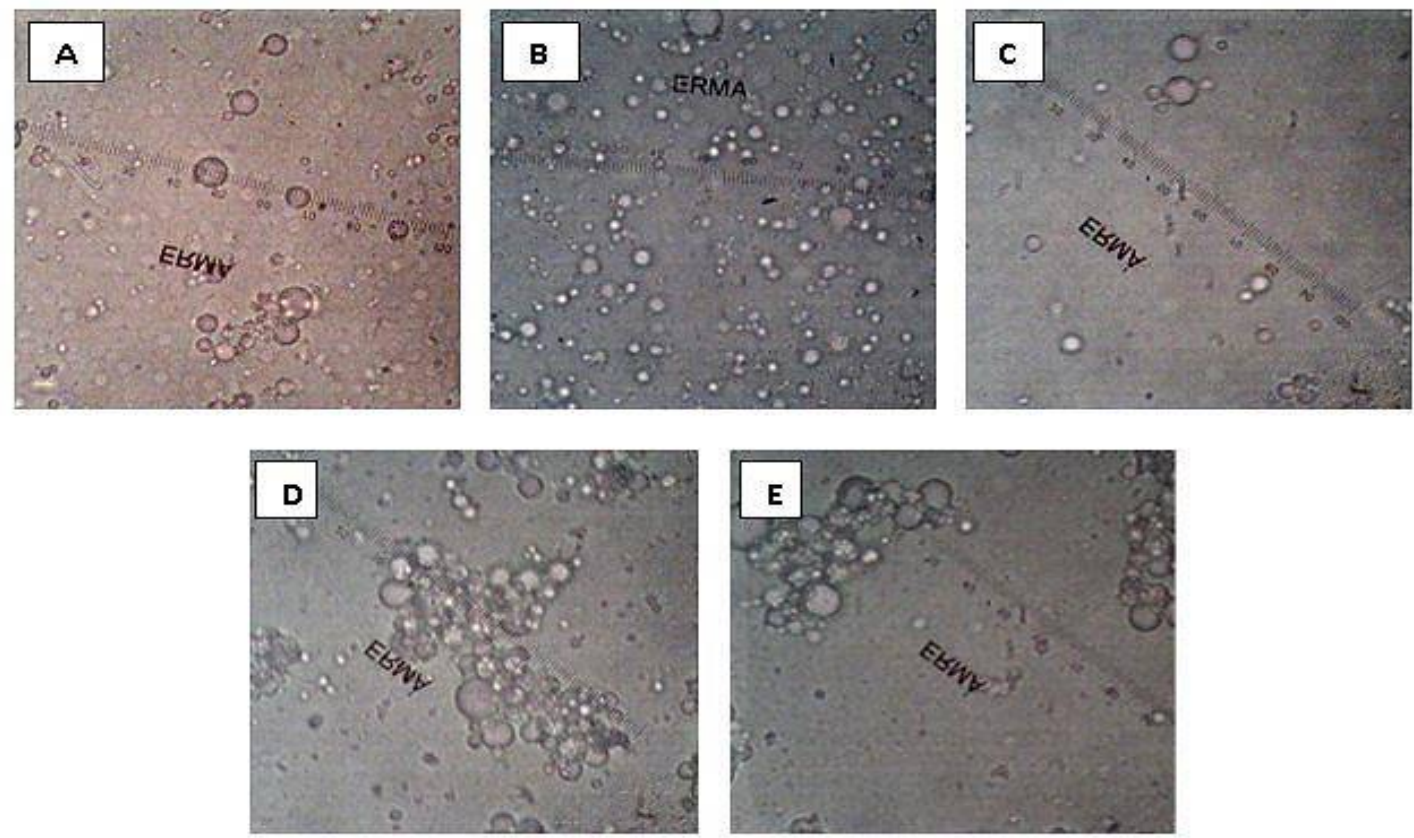

Figure 2: Micrographs of CS emulsion (A) Freshly prepared (B) after 12 weeks of storage at $8{ }^{\circ} \mathrm{C}(\mathrm{C})$ after 12 weeks of storage at $25{ }^{\circ} \mathrm{C}(\mathrm{D})$ after 12 weeks of storage at $40{ }^{\circ} \mathrm{C}(\mathrm{E})$ after 12 weeks of storage at $40{ }^{\circ} \mathrm{C} \pm 75 \%$ $\mathrm{RH}$

\section{Droplet size and shape}

The representative photomicrographs of freshly prepared formulation and after 12 weeks of various storage conditions are shown in Figure 2. The freshly prepared emulsion droplets exhibited spherical shape. The shape of the particles after 12 weeks storage at various conditions did not changed. The mean droplet size of emulsion was found to be within macroemulsion range (1 - 100 $\mu \mathrm{m})$ for 12 weeks of study when kept at different temperature and humidity conditions (Figure 3 ).
The mean droplet size for freshly prepared emulsion was $2.98 \pm 1.32 \mu \mathrm{m}$. After the completion of study the droplet size was $3.46 \pm$ $1.18,3.40 \pm 1.16,3.86 \pm 1.84$ and $3.94 \pm 1.82$ $\mu \mathrm{m}$ for formulation kept at $8,25,40^{\circ} \mathrm{C}$, and $40{ }^{\circ} \mathrm{C}$ $\pm 75 \% \mathrm{RH}$, respectively. There was no significant change $(p>0.05)$ observed after the study in mean droplet size when stored at 8 and $25{ }^{\circ} \mathrm{C}$ but accelerated conditions $\left(40{ }^{\circ} \mathrm{C}\right.$ and 40 ${ }^{\circ} \mathrm{C} \pm 75 \% \mathrm{RH}$ ) showed a relatively greater increase in droplet size. 


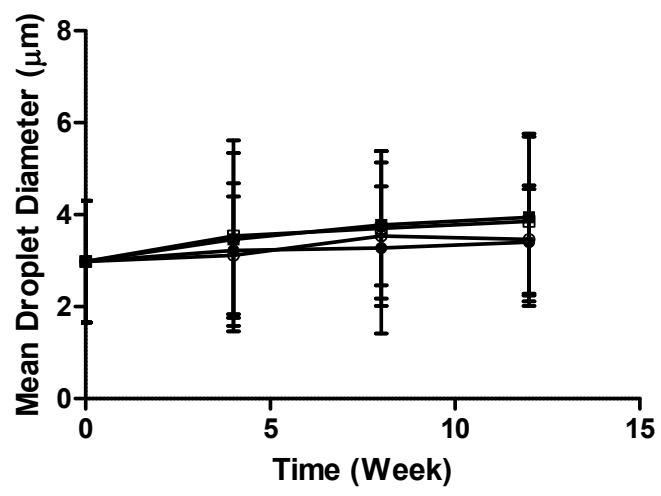

Figure 3: Mean droplet diameter at various time intervals.

\section{DISCUSSION}

DPPH method is a nonspecific, accurate and rapid method of determining antioxidant activity [16]. Good antioxidant activity of the extract may be attributed to the presence of polyphenols [17]. The presence of such compound makes CS extract a potential ingredient for cosmetic products to combat skin problems naturally.

The centrifugation test is an accelerated stability test which is based on the principle that two substances with different densities become separated under centrifugal force. These substances may be two immiscible liquids or a liquid and insoluble solid. Accelerated separation of the dispersed phase as a result of creaming or coalescence serves as a test to predict the stability of the emulsion [18]. In our study the formulation showed sufficient resistance to the destabilization phenomenon over the defined period at low and moderate temperatures. This might be because of either less density difference between the oil and aqueous phase or it may be because of strong interfacial film at the interface [19]. At higher temperatures slight phase separation might be because of lowering of viscosity of oil phase that resulted in the sedimentation of the heavier phase under centrifugal force [20-22].

Rheology is concerned with the manufacturing and application of the semisolid topical formulations. Rheological parameters are very crucial in determining the physical stability of the formulation during the shelf life. Flow index value less than 1 indicate departure from the Newtonian characteristics that is desirable for achieving a coherent film and quick flow ability of the topical formulation [23,24]. This study showed that non Newtonian, pseudoplastic behavior of the formulation did not change even under thermal stress, over time, demonstrating the physical stability. On the other hand, results of rheological study showed a decrease in consistency index during storage at various temperatures and agree with the results by other investigators [25].

Droplet size is one of the important characteristic of the topical formulation that contributes to the physical stability of dermal and cosmetic products. The small droplet size prevents the droplet coalescence and sedimentation against gravitational force [26]. Droplet size analysis in this study showed that the emulsion had a small droplet size in the range, desire able for topical emulsions. The extract loaded emulsions showed changes in only narrow ranges of droplet diameter that indicates that the formulation is fairly stable to destabilization under study conditions. On the other hand, the increase in mean droplet diameter was greater when formulation was stored at higher temperatures (40 ${ }^{\circ} \mathrm{C}$ and $\left.40{ }^{\circ} \mathrm{C} \pm 75 \% \mathrm{RH}\right)$. It has been stated that at higher temperatures, the viscosity of the continuous phase decline that may allow more frequent collision between the droplets and result in increased droplet size [27].

\section{CONCLUSION}

A W/O emulsion containing corn silk extract was evaluated for physical stability. The prepared corn silk extract W/O emulsion possesses good stability with adequate resistance to phase separation, pseudo plastic behavior and mean particle diameter in a narrow range over time. Thus, the developed topical formulation is a potential alternative for delivery of natural antioxidants for topical pharmaceutical and cosmetic applications.

\section{ACKNOWLEDGEMENT}

The authors would like to thank Professor Dr Mahmood Ahmad, Dean, Faculty of Pharmacy and Alternative Medicine, The Islamia University of Bahawalpur, Bahawalpur for his valuable guidance as well as Dr Saeed Ahmad, Principal, UCCM, The Islamia University of Bahawalpur, Bahawalpur for providing facilities for conducting a part of this work.

\section{DECLARATIONS}

\section{Conflict of Interest}

No conflict of interest associated with this work. 


\section{Contribution of Authors}

The authors declare that this work was done by the authors named in this article and all liabilities pertaining to claims relating to the content of this article will be borne by them.

\section{REFERENCES}

1. Sinko PJ, Singh Y. editors. Martin's Physical Pharmacy and Pharmaceutical Sciences: Physical Chemical and Biopharmaceutical Principles in the Pharmaceutical Sciences. Philadelphia: Lippincott Williams \& Wilkins; 2011; $p 410$

2. Gisby J, Bryant J. Efficacy of a new cream formulation of mupirocin: comparison with oral and topical agents in experimental skin infections. Antimicrob. Agents Chemother 2000; 44(2): 255-260.

3. Swarbrick J, Rubino JT, Rubino OP. Coarse dispersions. In: Troy DB, Remington JP, Beringer P. Remington: The Science and Practice of Pharmacy. 21st ed. Philadelphia: Lippincott Williams \& Wilkins 2006. p. 319337

4. Gillian ME. Emulsions and creams. In: Aulton ME, Taylor KM. editors. Aulton's pharmaceutics: the design and manufacture of medicines. 4th ed. Newyork: Churchill Livingstone Elsevier 2013. p. 435-464

5. Chen G, Tao D. An experimental study of stability of oilwater emulsion. Fuel Process. Technol 2005; 86(5): 499-508.

6. Kulmyrzaev A, Chanamai R, McClements DJ. Influence of $\mathrm{pH}$ and $\mathrm{CaCl}_{2}$ on the stability of dilute whey protein stabilized emulsions. Food Res Int 2000; 33(1): 15-20.

7. Rittié L, Fisher GJ. UV-light-induced signal cascades and skin aging. Ageing res rev 2002; 1(4): 705-720.

8. Trouba KJ, Hamadeh HK, Amin RP, Germolec DR. Oxidative stress and its role in skin disease. Antioxid Redox Signal 2002; 4(4): 665-673.

9. Mahmood T, Akhtar N, Khan BA, Khan HMS, Saeed T. Outcomes of $3 \%$ green tea emulsion on skin sebum production in male volunteers. Bosn J Basic Med Sci 2010; 10(3): 260-264

10. Chuarienthong $P$, Lourith $N$, Leelapornpisid $P$. Clinical efficacy comparison of anti-wrinkle cosmetics containing herbal flavonoids. Int J Cosmetic Sci 2010; 32(2): 99106.

11. Corazza M, Borghi A, Lauriola M, Virgili A. Use of topical herbal remedies and cosmetics: a questionnaire-based investigation in dermatology out-patients. J Eur Acad Dermatol Venereol 2009; 23(11): 1298-1303.

12. Maksimović Z, Malenčić $Ð$, Kovačević N. Polyphenol contents and antioxidant activity of Maydis stigma extracts. Bioresour Technol 2005; 96(8): 873-877.
13. Wang C, Zhang T, Liu J, Lu S, Zhang C, Wang E, et al. Subchronic toxicity study of corn silk with rats. J Ethnopharmacol 2011; 137(1): 36-43.

14. Liu J, Wang C, Wang Z, Zhang C, Lu S, Liu J. The antioxidant and free-radical scavenging activities of extract and fractions from corn silk (Zea mays L.) and related flavone glycosides. Food Chem 2011; 126(1): 261-269.

15. Rasul A, Akhtar N. Anti-aging potential of a cream containing milk thistle extract: Formulation and in vivo evaluation. Afr J Biotechnol 2014; 11(6): 1509-1515.

16. Meda A, Lamien CE, Romito M, Millogo J, Nacoulma OG. Determination of the total phenolic, flavonoid and proline contents in Burkina Fasan honey, as well as their radical scavenging activity. Food Chem 2005; 91(3): 571-577.

17. Tsao R. Chemistry and biochemistry of dietary polyphenols. Nutrients 2010; 2(12): 1231-1246.

18. Masson DS, Morais GG, de Morais JM, de Andrade FF, Dos Santos OD, de Oliveira WP, et al. Polyhydroxy alcohols and peach oil addition influence on liquid crystal formation and rheological behavior of $\mathrm{o} / \mathrm{w}$ emulsions. J Dispersion Sci Technol 2005; 26(4): 463468.

19. Jumaa M, Müller BW. Parenteral emulsions stabilized with a mixture of phospholipids and PEG-660-12hydroxy-stearate: evaluation of accelerated and longterm stability. Eur J Pharm Biopharm. 2002; 54(2): 207212.

20. Binks BP, Rocher A. Effects of temperature on water-inoil emulsions stabilised solely by wax microparticles. $J$ Colloid Interface Sci. 2009; 335(1): 94-104.

21. Anisa Al, Nour AH. Affect of Viscosity and Droplet Diameter on water-in-oil (w/o) Emulsions: An Experimental Study. J World Academy of Science Engineering and Technology 2010; 38: 692-694.

22. Herschel WH. The Change in Viscosity of Oils with the Temperature. Ind Eng Chem. 1922; 14(8): 715-722.

23. Guaratini $T$, Gianeti MD, Campos PM. Stability of cosmetic formulations containing esters of Vitamins $E$ and A: chemical and physical aspects. Int J Pharm. 2006; 327(1): 12-16.

24. Gaspar L, Campos PM. Rheological behavior and the SPF of sunscreens. Int J Pharm. 2003; 250(1): 35-44.

25. Korhonen M, Hellen L, Hirvonen J, Yliruusi J. Rheological properties of creams with four different surfactant combinations-effect of storage time and conditions. Int $\mathrm{J}$ Pharm. 2001; 221(1): 187-196.

26. Yang $Y$, Leser ME, Sher AA, McClements DJ. Formation and stability of emulsions using a natural small molecule surfactant: Quillaja saponin (Q-Naturale®). Food Hydrocolloid. 2013; 30(2): 589-596.

27. Dhanorkar V, Gawande R, Gogte B, Dorle A Development and characterization of rosin-based polymer and its application as a cream base. J Cosmet Sci. 2002; 53(4): 199-208. 